\title{
Embryonal risks in gestational diabetes mellitus
}

\author{
Charles Savona-Ventura, ${ }^{\mathrm{a}, *}$, Miriam Gatt ${ }^{\mathrm{b}}$ \\ ${ }^{a}$ Diabetic Pregnancy Joint Clinic, Department of Obstetrics-Gynaecology, St. Luke's Teaching Hospital, \\ Gwardamangia, Malta \\ ${ }^{\mathrm{b} D e p a r t m e n t}$ of Health Information, Gwardamangia, Malta
}

Accepted 22 April 2004

\begin{abstract}
Diabetes mellitus is generally associated with a higher incidence of early pregnancy loss and congenital anomalies, though this relationship should be strictly restricted to patients with previously existing diabetes. In gestational diabetes mellitus, which often develops during the third trimester, no such relationship should exist, though the birth of a previous infant with a congenital anomaly is often assumed to be a risk factor for gestational diabetes.

Objective: The study attempts to analyse the congenital anomaly rate in women with gestational diabetes and compare this to the rates in women known to have normal glucose tolerance.

Results: The prevalence of infants/fetuses with congenital anomalies born to women with gestational diabetes amounted to $4.48 \%$, a rate similar to that recorded in women with normal glucose tolerance (4.54\%).

Conclusions: The development of gestational diabetes, in contrast to pre-existing diabetes, does not appear to be associated with an increased risk for teratogenesis.
\end{abstract}

(C) 2004 Elsevier Ireland Ltd. All rights reserved.

Keywords: Diabetic-pregnancy; Malformations; Diabetes mellitus

\section{Introduction}

Evidence demonstrates that women with diabetes mellitus have a greater risk of spontaneous abortions and congenital malformations. This risk in women with pre-existing

* Corresponding author. "NorthWynds" 7 Antonio Zammit Street, Gharghur Nxr08, Malta. Fax: +356 21244766.

E-mail address: saven@vol.net.mt (C. Savona-Ventura).

0378-3782/\$ - see front matter C 2004 Elsevier Ireland Ltd. All rights reserved. doi:10.1016/j.earlhumdev.2004.04.007 
DM has been associated to poor glycaemic control during the embryonic period, particularly in the first few weeks after conception. A similar risk has been described for women who develop gestational diabetes later on in the pregnancy suggesting that the mechanism for embryonal dysfunction may involve a genetic or hormonal predisposition [1]. Similar increased risks for early pregnancy loss $(\times 5.5$-fold increase $)$ and teratogenesis $(\times 1.6$-fold increase) have been previously observed in Maltese pregnant women who develop gestational diabetes [2]. The Maltese population in the Central Mediterranean has been repeatedly shown to have a high prevalence of carbohydrate metabolism problems, which is reflected in the pregnant population [3]. The present study attempts to identify whether gestational diabetes is truly a risk factor for the development of congenital anomalies in a relatively closed population with a high prevalence of NIDDM.

\section{Material and methods}

All pregnant women $(n=1263)$ undergoing a 75 -g oral glucose tolerance test [oGTT] in the third trimester at St. Luke's Teaching Hospital (Malta) during the period 1996-2000 were included in the study. An OGTT is generally performed on women identified as being at risk of GDM on the basis of standard "historical-clinical" risk factors, the test being generally performed in the late second or the third trimester of pregnancy. In our experience, this screening procedure identifies all the cases of severe GDM [2-h value $\geq 11.0 \mathrm{mmol} / \mathrm{l}$ ] and about $20 \%$ mild GDM [2-h value $8.6=10.9 \mathrm{mmol} / 1$ ] [2]. The majority of the women were lost to postnatal follow-up, however none of the patients had evidence of significant recurrent first or early second trimester glycosuria. This study population included 972 women with normal glucose tolerance, and 291 women with oGTT glucose values in line with the recommendations made by the American Diabetes Association. The infant outcome of the current pregnancy of these patients was traced from the Malta Congenital Anomalies Register kept by the Department of Health Information (Malta) that registers all infants or fetuses with malformations born on the Maltese Islands since 1993. Statistical significance was tested using the Chi-square test analysis was using MedCalc (ver.4.16) statistical package. A probability value of $<0.05$ was taken to represent a significant correlation. The work was approved by the Ethics Committee of the Faculty of Medicine and Surgery of the University of Malta. The subjects gave informed consent to the collection of the databases and the data analysis.

\section{Results}

The prevalence of infants/fetuses born with one or more anomalies to women with gestational diabetes mellitus during 1996-2000 was estimated at 4.54\%, while that in women with normal glucose tolerance was estimated at $4.48 \%$ (Table 1). The small difference was not statistically significant ( $p=0.9066$, contingency coefficient $=0.003$ ). The overall prevalence of congenital anomalies in the study population (4.74\%) was higher though not statistically significant ( $p=0.1692$, contingency coefficient $=0.007$ ) than that registered in the Maltese Islands during the period 1993-2000 (3.74\%). 
Table 1

Congenital anomalies incidence rates by carbohydrate tolerance status

\begin{tabular}{lccc}
\hline & $\begin{array}{l}\text { Anomalies present } \\
\text { pregnancy }\end{array}$ & $\begin{array}{l}\text { Normal present } \\
\text { pregnancy }\end{array}$ & $\begin{array}{l}\text { Rate of infants/fetuses } \\
\text { with anomalies (\%) }\end{array}$ \\
\hline - Normal tolerance & 44 & 928 & 4.54 \\
- Gestational diabetes & 13 & 278 & 4.48 \\
Total & 57 & 1206 & 4.74 \\
Total population 1993-2000 & 1408 & 36,224 & 3.74 \\
\hline
\end{tabular}

The commonest type of abnormality noted in the study group was cardiovascular defects which accounted for $64.7 \%$ in women with abnormal carbohydrate metabolism and $54.7 \%$ in women with normal carbohydrate metabolism (Table 2). The differences were however not statistically significant ( $p=0.4623$, contingency coefficient $=0.075$ ). When compared to the overall population pattern of the types of congenital malformations reported in the Maltese Islands during the period, it would appear that cardiovascular anomalies in women diagnosed as suffering from GDM $[n=22 ; 64.7 \%]$ were more frequent than the number reported in the general population $[n=583 ; 42.3 \%]$, the difference being statistically significant $(p=0.0167$, contingency coefficient $=0.065)$. The congenital heart defects in babies of women with GDM included 11 cases of Atrial Septal Defect Ostium Secundum Type; 5 cases of Ventricular Septal Defect; 2 cases of Anomalies of Pulmonary Valve; 2 cases of Patent Ductus Arteriosus; 1 case of Coarctation of Aorta and 1 case registered as Other Malformations of the Heart. The other types of anomalies did not show any statistically significant difference in relative frequency rates.

Table 2

Type of congenital anomalies by carbohydrate tolerance status [includes cases with multiple lesions]

\begin{tabular}{|c|c|c|c|c|c|c|}
\hline \multicolumn{2}{|c|}{ Malformation type } & \multicolumn{2}{|c|}{ Abnormal oGTT } & \multicolumn{2}{|c|}{ Normal oGTT } & \multirow{2}{*}{$\begin{array}{l}\begin{array}{l}\text { Statistical } \\
\text { significance }\end{array} \\
p \text { value }\end{array}$} \\
\hline ICD code & & No. & $\%$ & No. & $\%$ & \\
\hline $7400-7420$ & Neural tube defects & 0 & 0.00 & 1 & 1.56 & 0.7519 \\
\hline $7421-7429$ & Other anomalies of nervous system & 1 & 2.94 & 1 & 1.56 & 0.7756 \\
\hline $7430-7449$ & Eye, ear, face and neck & 1 & 2.94 & 1 & 1.56 & 0.7756 \\
\hline $7450-7479$ & Cardiovascular system & 22 & 64.71 & 35 & 54.69 & 0.4623 \\
\hline $7480-7489$ & Respiratory system & 0 & 0.00 & 0 & 0.00 & - \\
\hline $7490-7493$ & Cleft lip/palate & 0 & 0.00 & 3 & 4.69 & 0.5062 \\
\hline $7500-7509$ & Upper alimentary tract & 0 & 0.00 & 1 & 1.56 & 0.7519 \\
\hline $7510-7519$ & Other digestive system & 2 & 5.88 & 4 & 6.25 & 0.7129 \\
\hline $7520-7529$ & Genital organs & 0 & 0.00 & 1 & 1.56 & 0.7519 \\
\hline $7530-7539$ & Urinary system & 1 & 2.94 & 1 & 1.56 & 0.7756 \\
\hline $7540-7559$ & Musculoskeletal system & 2 & 5.88 & 5 & 7.81 & 0.9539 \\
\hline $7560-7569$ & Other musculoskeletal & 0 & 0.00 & 1 & 1.56 & 0.7519 \\
\hline $7571-7579$ & Integument & 1 & 2.94 & 1 & 1.56 & 0.7756 \\
\hline $7580-7589$ & Chromosomal anomalies & 2 & 5.88 & 4 & 6.25 & 0.7129 \\
\hline $7593-7599$ & Other congenital anomalies & 0 & 0.00 & 3 & 4.69 & 0.5062 \\
\hline \multirow[t]{3}{*}{$7607-7786$} & Conditions in perinatal period & 0 & 0.00 & 2 & 3.13 & 0.7756 \\
\hline & Miscellaneous & 2 & 5.88 & 0 & 0.00 & 0.2314 \\
\hline & Total & 34 & 100.00 & 64 & 100.00 & \\
\hline
\end{tabular}




\section{Discussion}

A growing body of evidence has suggested an increased risk of embryonic development problems in the conceptus of diabetic mothers. The risk of early pregnancy loss and teratogenesis in women with pre-existing diabetes has been clearly demonstrated and has been attributed to poor glycaemic control during the embryonic period $[1,4]$. Surprisingly, similar elevated risks for teratogenesis have been described in women who develop gestational diabetes later on during their pregnancy and whose glycaemic control in the first trimester was in no way disrupted. The 1977-1981 Northwestern University Medical Centre (USA) study demonstrated a 4.5-fold increase in anomalies in infants of IDDM mothers and also a two-fold increase in birth defects in women suffering from gestational diabetes [5]. In the Maltese population, women with gestational diabetes were shown to have a non-statistically significant 1.6-fold increased risk of having a congenital anomaly. In addition, these women had a statistically significant 5.5-fold increased risk of having a history of previous early pregnancy loss [2]. The apparent association of early pregnancy dysfunction causing early pregnancy loss and teratogenesis in women who develop gestational diabetes and whose glycaemic status in the embryonic period is well maintained suggests that other mechanisms other than metabolic derangements may be play a role in the aetiology. The possibility of a "diabetic gene" responsible for an increase in malformations in infants of diabetic mothers has been raised, even though the evidence from epidemiological and animal studies suggests otherwise [1].

The present study has failed to identify any significant increased risk between teratogenesis and gestational diabetes. The previously reported statistically nonsignificant higher anomaly risk in GDM Maltese women may have been simply the result of study design and study population size. The present study shows an apparently increased anomaly rate in the study population when compared to the National data. It is probable that this apparent higher rate is due to bias caused by a greater likelihood that elderly women with antenatal problems, including a diagnosis of malformation, undergo screening for DM with a glucose tolerance test. Similarly, the noted apparent higher frequency of anomalies of the cardiovascular system in the infants of women diagnosed as suffering from GDM when compared to the overall population may be due to the increased screening that infants of GDM mothers receive. These infants are often transferred to the Special Care Baby Unit in the early neonatal period, where specialized medical staff is more likely to identify minor cardiovascular lesions that are proven to be of no clinical significance and that disappear spontaneously after a few days. The large majority of anomalies noted in the study population referred to such minor lesions. Another possibility for the noted higher prevalence of cardiac defects may be that the minor biochemical alterations that are known to occur in infant of GDM mothers delay the conversion from a fetal cardiovascular system to a neonatal one. There is however to date no proof that the known associated biochemical alterations may in fact be responsible.

The lack of association between teratogenesis and subsequent development of gestational diabetes suggests that the reported high early pregnancy loss in women who subsequently develop gestational diabetes is probably unrelated to any inherent heritable factors. There may have been some bias in the observations since in our experience the screening method in force only identifies about $20 \%$ of the mild cases of GDM [ $2-h$ value 
8.6-10.9 $\mathrm{mmol} / \mathrm{l}$ ], these cases being then considered as having a normal metabolic profile. A possible postulate for the relationship between a higher risk for early fetal loss and gestational diabetes could be the relationship between spontaneous abortions, polycystic ovarian disease and insulin resistance. Women with polycystic ovarian disease [PCOD] are generally infertile, but when pregnancy is achieved this is more likely to terminate in a spontaneous abortion. The higher abortion rates have been correlated to the high basal concentrations of lutenizing hormone that inhibits the oocyte maturation inhibitor leading to premature reactivation of meiosis, karyotypic abnormalities and embryo-fetal loss. In spite of the large increase in insulin secretion observed during pregnancy, patients with PCOD have been shown to develop during their pregnancy a derangement of glycaemic control probably related to their pregestational insulinemic status $[6,7]$.

\section{References}

[1] Comb CA, Kitzmiller JL. Spontaneous abortion and congenital malformations in diabetics. Bailliere's Clin Obstet Gynaecol 1991;5(2):315-31.

[2] Savona-Ventura C, Schranz AG, Chircop M. Risk factors for gestational impaired glucose tolerance in the Maltese population: a cross-sectional study. J Obstet Gynaecol 2001;21(6):591-4.

[3] Katona G, Aganovic I, Vuscan V, Skrabalo Z. The National Diabetes Programme in Malta-Final Report Phases I and II. WHO.NCD/OND/DIAB/83.2. Geneva: WHO; 1983.

[4] Freinkel N, Lewis NJ, Akazawa S, Roth SI, Gorman L. The honey bee syndrome-implications of the teratogenicity of mannose in rat embryo culture. N Engl J Med 1984;310:223-30.

[5] Simpson JL, Elias S, Martin AO, et al. Diabetes in Pregnancy, Northwestem University series (1977-1981): I. Prospective study of anomalies in offspring of mothers with diabetes mellitus. Am J Obstet Gynecol $1983 ; 146: 263-70$.

[6] Ron-El R. Complication of ovulation induction. Bailliere's Clin Obstet Gynaecol 1993;7(2):435-53.

[7] Lanzone A, Caruso A, Di-Simone N, De-Carolis S, Fulghesu AM, Mancuso S. Polycystic ovary disease. A risk factor for gestational diabetes? J Reprod Med 1995;40(4):312-6. 